Eur. J. Clin. Chem. Clin. Biochem.

Vol. 31, 1993, pp. 197-204

(C) 1993 Walter de Gruyter \& Co.

Berlin - New York

\title{
The Plasma Amino Acid Profile and its Relationships to Standard Quantities of Liver Function in Infants and Children with Extrahepatic Biliary Atresia and Preterminal Liver Cirrhosis
}

\author{
By D. J. Byrd, Annegret Wiltfang, B. Rodeck, Astrid Latta, M. Burdelski and J. Brodehl
}

Medizinische Hochschule Hannover, Kinderheilkunde II, Pädiatrische Nieren- und Stoffivechselkrankheiten, Hannover, Bundesrepublik Deutschland

(Received May 19/July 21, 1992)

\begin{abstract}
Summary: The absolute and relative concentrations of 16 plasma amino acids in 48 mostly dystrophic infants and children (median of age $1 \frac{1}{2}$ years) with extrahepatic biliary atresia and mainly stable preterminal cirrhosis were compared with those of controls. Patient plasma amino acid data were analysed statistically for diagnostic usefulness and correlated with standard biochemical quantities of liver function and of liver perfusion. In the patients the total amounts of non-essential and essential amino acids were reduced by $19 \%$, and with the same significance $(\mathrm{p}<0.0005)$. Plasma tyrosine was increased $(+40 \%)$, while taurine $(-44 \%)$ and branched chain amino acids $(+28.8 \%$ to $-34.7 \%)$ were decreased. Methionine values varied widely. In the molar fractional plasma amino acid profile, only alanine, valine, and leucine were decreased, while threonine, methionine, tyrosine, phenylalanine, ornithine, and serine were increased. Discriminate function analysis showed that the plasma amino acid data discriminated $93.8 \%$ of the patients from controls. The concentrations of some amino acids in plasma seemed to have been influenced by protein-calorie deficiency in the patients. The valine/tyrosine ratio and the Fischer index (ratio branched chain/aromatic amino acids) were significantly reduced in the patients versus controls $(1.54 \pm 0.55$ vs $3.08 \pm 0.55$ and $1.66 \pm 0.39$ vs $3.00 \pm 0.48)$. A number of significant correlations (range of $\mathrm{r}$ : $0.37-0.59, \mathrm{p}<0.05,30-48$ data pairs) were calculated between plasma amino acid data and several standard biochemical quantities of liver function. The statistical analyses also showed that the Fischer index began to decrease gradually and linearly early in the progression of liver failure. It is concluded that plasma amino acid data can be useful in the evaluation of the progression of liver failure and possibly of the nutritional status in liver transplant candidates with biliary atresia.
\end{abstract}

\section{Introduction}

Extrahepatic biliary atresia is a congenital structural defect of the hepatic biliary tree. Its frequency is estimated to be $1: 8000$ to $1: 15000$. It is responsible for 75 to $80 \%$ of the cases of conjugated hyperbilirubinaemia in children $(1,2)$. In the natural course of extrahepatic biliary atresia, 70 to $90 \%$ of cases die within 2-3 years (3). Affected patients may benefit, for a time, from hepatoportoenterostomy (4), but most eventually develop biliary cirrhosis and progressive liver failure $(5,6)$. The only definitive therapy appears to be liver transplantation $(3,6)$. Lack of donor liver and low body weight in recipients are serious problems, so that staging and optimal nutritional care of the chronically malnourished transplantation candidates are vital $(1,3)$. Single laboratory findings will usually not be indicative of impending terminal liver failure in extrahepatic biliary atresia (3).

In adult cirrhotics, plasma concentrations of the aromatic amino acids are increased and those of branched chain amino acids are decreased. Methionine can be markedly elevated (7-9). The Fischer index (the ratio of the sum of the concentrations of 
the branched chain amino acids to that of phenylalanine plus tyrosine) is subnormal and may be correlated with liver histology $(10,11)$ and with hepatic synthetic capacity (9). One publication (12) has dealt with this subject in children with extrahepatic biliary atresia and cirrhosis. In these 26 patients, 6 of whom suffered from terminal hepatic failure, total free plasma amino acids were significantly elevated; raised plasma methionine showed the greatest deviation from normal, and their plasma taurine was significantly decreased. The Fischer index was depressed, as in adults.

We present a retrospective analysis of data on 16 plasma amino acids in infants and children with extrahepatic biliary atresia and preterminal cirrhosis. The aims of the study were to detect early possibly treatable amino acid imbalances or deficiencies and to probe the usefulness of plasma amino acid data in the diagnosis and monitoring of progression of liver failure in extrahepatic biliary atresia liver transplantation candidates.

\section{Patients and Methods}

All 48 children ( 27 females, 21 males) had been evaluated during the time period 1983 to 1988 at our hospital, as liver transplantation candidates. Extrahepatic biliary atresia had been confirmed by intraoperative cholangiogram and by liver biopsy. Seven patients also had intrahepatic biliary hypoplasia. Cirrhosis had developed in 44 patients, despite previous hepatoportoenterostomy, and in 4 others without such surgery. The me- dian age was $1 \frac{1}{12}$ years ( 5 months to $7 \% 12$ years) and the median of postoperative time in respective patients was 11 months ( 2 months to $7^{2} / 12$ years) at the time of the plasma amino acid analyses. The median of body weight on standard growth curves (13) was at the 5th percentile (range 3id-97th percentile) for age. Higher body weight in some cases was due to ascites. All patients were on age-adequate oral nutrition (1.5 to $2 \mathrm{~g}$ of protein $/ \mathrm{kg} \cdot \mathrm{d}$ ) and supplemental medium chain triacylglycerols. The medicinal treatment consisted of (No./total): diuretics 23/48; vitamins $A, D, E 31 / 48$; vitamin $\mathrm{K} 25 / 48$; phenobarbital 17/48; cholestyramin 16/48; pancreas enzymes 11/48; antibiotics 17/48; antacids $6 / 48$.

\section{Evaluation of liver function}

Table 1 summarises the evaluation of liver function by standard laboratory quantities. Total protein, albumin, prothrombin time (Quick), partial thromboplastin time, total bilirubin, cholinesterase activity, as well as activities of the serum liver enzymes: aspartate aminotransferase, alanine aminotransferase, glutamate dehydrogenase, alkaline phosphatase und $\gamma$-glutamyltransferase, were determined by standard methods. Lipoprotein $\mathrm{X}$ and total serum bile acids were determined according to Talafant \& Tovarek (14), with the Merck (Darmstadt, Germany) enzymatic-colorimetric kit according to the instructions of the manufacturer.

Extrahepatic blood flow was determined from the clearance rate of an i.v. bolus of ${ }^{99} \mathrm{Tc}$-labelled human serum albumin. The rate constant " $k$ " for the monoexponential equation, which describes the clearance rate of an i.v. bolus of ${ }^{99} \mathrm{Tc}$-labelled human serum albumin, is directly proportional to estimated hepatic blood flow $(15,16)$ and is referred to hereafter as estimated hepatic blood flow(k). The portal venous fraction of total hepatic perfusion was measured as described after an i.v. bolus of ${ }^{99} \mathrm{Tc}$-labelled diethylenetriamine-pentaacetic acid (16).

The 48 patients had been scored as follows, according to a standardised prognostic risk score (3), representing increasing priority for liver transplantation: 0: $16(33.3 \%) ; 1: 16(33.3 \%)$; 2: $10(20.8 \%)$; 3: $6(12.5 \%)$

Tab. 1. Clinical chemical and scintigraphic data on hepatic synthetic function, hyperammonaemia, hepatocellular necrosis, cholestasis, estimated hepatic blood flow and portal venous fraction of liver perfusion in the children with biliary atresia and liver cirrhosis, compared with laboratory reference ranges.

\begin{tabular}{|c|c|c|c|c|c|}
\hline \multirow[b]{2}{*}{ Albumin $(\mathrm{g} / \mathrm{l})$} & \multicolumn{2}{|c|}{ Patient values } & \multirow{2}{*}{$\frac{\mathrm{N}}{47}$} & \multicolumn{2}{|c|}{ Reference range } \\
\hline & 36 & $\pm \quad 5.1$ & & 35 & -50 \\
\hline Partial thromboplastin time (s)' & 42.4 & $\pm \quad 8.8$ & 47 & 33 & -40 \\
\hline Cholinesterase $(\%)^{2}$ & 71.4 & \pm 34.4 & 48 & & \\
\hline Quick (\%) & 74.0 & \pm 19.1 & 48 & 70 & -120 \\
\hline Ämmonia, venous $(\mu \mathrm{mol} / \mathrm{l})$ & 60.6 & \pm 26.1 & 44 & 20 & -51 \\
\hline Aspartate aminotransferase $(\mathrm{U} / \mathrm{l})$ & 123 & \pm 50 & 48 & & $-15^{3}$ \\
\hline Alanine aminotransferase (U/l) & 97 & \pm 48 & 48 & & $-17^{3}$ \\
\hline Glutamate dehydrogenase (U/1) & 24.1 & \pm 19.6 & 48 & & $-3^{3}$ \\
\hline Bilirubin $(\mu \mathrm{mol} / \mathrm{l})$ & 240 & \pm 44 & 48 & & $-17^{3}$ \\
\hline Alkaline phosphatase (U/I) & 1439 & \pm 563 & 48 & & -190 \\
\hline Lipoprotein-X $(\mathrm{g} / \mathrm{l})$ & 4.7 & $\pm \quad 3.8$ & 30 & 0.01 & $-\quad 0.06$ \\
\hline Total serum bile acids $(\mu \mathrm{mol} / \mathrm{l})$ & 243 & \pm 125 & 45 & 6.0 & $\pm \quad 2.8$ \\
\hline Estimated hepatic blood flow(k) $\left(\min ^{-1}\right)$ & 0.73 & $\pm \quad 0.29$ & 38 & 0.8 & $=1.2$ \\
\hline Portal venous fraction of liver perfusion (\%) & 19.4 & \pm 11 & 45 & 70 & \\
\hline
\end{tabular}

125 patients were receiving supplemental vitamin $\mathrm{K}$

${ }^{2}$ During the period of study the substrate used to measure cholinesterase activity was changed from acetylthiocholine to butyrylthiocholine. Therefore, for comparability, the patient values are expressed as percent of the respective lower normal value, $1900 \mathrm{U} / \mathrm{l}$ or $3.5 \mathrm{kU} / \mathrm{l}$, respectively.

3 Upper limits of normal.

$\mathrm{N}=$ number of patients investigated 


\section{Amino acid analysis}

A laboratory reference of 27 healthy age-matched children $(13 \%, 14 \delta ;$ median age $1 \% / 12$ years) served as a control collective. Heparinised venous blood samples were collected after an overnight fast. When amino acid analysis was not immediately possible, blood plasma was kept frozen at $-20^{\circ} \mathrm{C}$ or below. Plasma was deproteinised by addition of an equal volume of aqueous $50 \mathrm{~g} / \mathrm{l}$ sulphosalicylic acid, then centrifuged. An aliquot of the supernatant was diluted with an equal volume of lithium citrate loading buffer. The analyses were carried out with the Biotronik (Munich, Germany) models LC 6000 and LC 2000 according to the manufacturer's instructions. The day to day coefficients of variation for individual amino acids in a reference plasma sample ranged between 3 and $6 \%$.

Twenty nine $(60.4 \%)$ of the amino acid determinations were performed on the same blood samples taken for clinical chemical determinations. Seven $(14.6 \%)$ were performed on samples collected within the same $24 \mathrm{~h}$ and $9(18.8 \%)$ others were performed on samples taken within the same $48 \mathrm{~h}$ as the samples for clinical chemistry. In the case of $3(6.3 \%)$ samples this time difference exceeded 8 days. Because some samples were stored up to 1 month prior to analysis, and because many samples had not been immediately deproteinised, glutamine, glutamic acid, cystine and tryptophan were not evaluated. Citrulline values were not available in the greater proportion of controls, and they were therefore excluded. Taurine was excluded from total free plasma amino acids and from the molar fraction analysis, as plasma values were available for only 17 of the extrahepatic biliary atresia patients.
We compared the mean concentrations of 16 individual plasma amino acids; total free plasma amino acids; and the mean molar fractions of individual amino acids (individual molar concentrations of amino acids over molar total of amino acids). We also examined the data for those amino acids which best discriminated patients from controls. Total free plasma amino acids was correlated with body weight percentiles. All individual amino acid data, the Val/Tyr ratio and the branched chain amino acids/aromatic amino acids ratio (Fischer index) were correlated with standard biochemical quantities of residual hepatic function (tab. 1), in the patients as a group, and in subgroups of patients at different stages of liver failure.

\section{Statistical analysis}

Mean values and standard deviation were used for normally distributed data. Differences between mean values of data sets were anlaysed for significance by t-test with the $p$ value set at less than 0.05 . Discriminate function analysis was used to determine those amino acids which were chiefly responsible for the differences between the patient versus the control group. Interdependence between pairs of data sets was analysed via linear regression analysis and the Pearson coefficient of correlation. Linear correlations between mutually dependent variables was expressed as the correlation coefficient " $r$ ". The SPSS software (SPSS Inc., Gorinchen, The Netherlands) licenced at the Medizinische Hochschule Hannover (SPSS-X, Schubö 1984) was used for all statistical analyses.

Tab. 2. Comparison of concentrations of 16 individual amino acids and total concentration of free amino acids, free essential amino acids and free non-essential amino acids in plasma of children with extrahepatic biliary atresia versus a control collective.

\begin{tabular}{|c|c|c|c|c|c|}
\hline \multirow[t]{2}{*}{ Amino acid } & \multicolumn{2}{|l|}{$\begin{array}{l}\text { Patients } \\
(n=48)\end{array}$} & \multicolumn{2}{|l|}{$\begin{array}{l}\text { Controls } \\
(\mathrm{n}=27)\end{array}$} & \multirow[t]{2}{*}{$\mathrm{p}<$} \\
\hline & $\begin{array}{l}\overline{\mathrm{x}} \\
(\mu \mathrm{mol} / \mathrm{l})\end{array}$ & $\begin{array}{l}\mathrm{SD} \\
(\mu \mathrm{mol} / 1)\end{array}$ & $\begin{array}{l}\overline{\mathrm{x}} \\
(\mu \mathrm{mol} / \mathrm{l})\end{array}$ & $\begin{array}{l}\mathrm{SD} \\
(\mu \mathrm{mol} / 1)\end{array}$ & \\
\hline Taurine & 42.7 & 18.7 & 76.5 & 21.3 & 0.0005 \\
\hline Threonine & 107.8 & 34.7 & 105.2 & 30.9 & ns \\
\hline Serine & 124.1 & 33.3 & 135.0 & 35.5 & ns \\
\hline Proline & 133.1 & 48.1 & 185.3 & 49.2 & 0.0005 \\
\hline Glycine & 185.7 & 42.3 & 221.1 & 60.5 & 0.05 \\
\hline Alanine & 181.8 & 54.6 & 275.7 & 58.7 & 0.0005 \\
\hline Valine & 130.6 & 28.3 & 196.6 & 39.5 & 0.0005 \\
\hline Methionine & 27.1 & 14.3 & 22.8 & 6.6 & \\
\hline Isoleucine & 39.2 & 9.7 & 55.2 & 14.1 & 0.0005 \\
\hline Leucine & 68.0 & 17.3 & 104.3 & 23.2 & 0.0005 \\
\hline Tyrosine & 92.2 & 30.6 & 64.9 & 12.9 & 0.0005 \\
\hline Phenylalanine & 56.5 & 13.7 & 53.7 & 13.1 & ns \\
\hline Ornithine & 74.6 & 24.7 & 69.6 & 26.2 & \\
\hline Lysine & 115.1 & 24.6 & 144.2 & 29.1 & 0.0005 \\
\hline Histidine & 61.4 & 12.8 & 80.7 & 24.0 & 0.0005 \\
\hline \multirow[t]{2}{*}{ Arginine } & 54.3 & 22.8 & 70.2 & 26.0 & 0.05 \\
\hline & Patients & $\mathrm{N}$ & Controls & $N$ & $\mathrm{p}<$ \\
\hline $\begin{array}{l}\text { Total free amino acids }(\mu \mathrm{mol} / \mathrm{l}) \\
\text { fraction of controls }\end{array}$ & $\begin{array}{c}1443 \pm 230 \\
0.809\end{array}$ & 45 & $1783 \pm 270$ & 21 & 0.0005 \\
\hline $\begin{array}{l}\text { Total essential amino acids } \\
\text { fraction of controls }\end{array}$ & $\begin{array}{c}544 \pm \\
0.798\end{array}$ & 47 & $682 \pm 117$ & 25 & 0.0005 \\
\hline $\begin{array}{l}\text { Total non-essential amino acids }{ }^{2} \\
\text { fraction of controls }\end{array}$ & $\begin{array}{l}907 \pm 139 \\
0.823\end{array}$ & 45 & $1102 \pm 157$ & 21 & 0.0005 \\
\hline
\end{tabular}

\footnotetext{
1 Includes isoleucine, leucine, lysine, methionine, phenylalanine, threonine, and valine. Tryptophan was not determined.

2 Includes alanine, arginine, glycine, histidine, ornithine, proline, serine and tyrosine. Citrulline was omitted.
} 


\section{Results}

The concentrations of 16 plasma amino acids in patients and controls are listed in table 2 and a graphical summary is presented in figure 1 . In the extrahepatic biliary atresia patients, total free plasma amino acids (tab. 2) was significantly lower than in controls by about $19 \%$. Essential and non-essential amino acids were lower by almost the same amount. The mean concentration of plasma taurine in 17 extrahepatic biliary atresia patients was only about $44 \%$ $(p<0.0005)$ of the control value. The absolute concentrations of proline, glycine, alanine, valine, isoleucine, leucine, lysine, histidine, and arginine showed various degrees of reduction, which were always significant. The absolute concentration of tyrosine was increased on average by over $40 \%(p<0.0005)$. Individual methionine values varied widely, while the mean concentration was in the upper range of normal but not significantly different from the control value.

As shown in figure 1, the molar fractions of threonine, serine, methionine, tyrosine, phenylalanine, ornithine, but not of glycine, were significantly raised in the extrahepatic biliary atresia group. In contrast to the absolute plasma amino acid profile, only the contributions of alanine, leucine and valine were significantly reduced in the molar fractional plasma amino acid profile.
Plasma valine correlated strongly with leucine in both controls $(r=0.64, \quad p<0.0005)$ and patients $(r=0.69, p<0.0005)$. In controls, valine was correlated strongly with isoleucine $(r=0.73$, $p<0.0005)$, and isoleucine with leucine $(r=0.75$, $\mathrm{p}<0.0005$ ). In the patients, both of the latter correlations were still statistically significant, but $r$ was smaller $(r=0.55, p<0.0005)$. Other correlations between concentrations of individual amino acids were not statistically significant.

Discriminate function analysis of amino acid data from extrahepatic biliary atresia patients and controls showed that valine, tyrosine, alanine, isoleucine, and histidine, in that order, were chiefly responsible for quantitative differences in the plasma amino acid profile in extrahepatic biliary atresia patients versus controls. When these 5 amino acids were used simultaneously as multivariant discriminators on the common data pool, it was possible to assign $45(93.8 \%)$ of the 48 extrahepatic biliary atresia patients and 26 $(96.3 \%)$ of the controls correctly to their group of origin. The mean value of the Fischer index (3.00 \pm 0.48 vs. $1.66 \pm 0.39$ ) (fig. 2 ) and the valine/tyrosine ratio $(3.08 \pm 0.55$ vs $1.54 \pm 0.55)$ were significantly depressed in the extrahepatic biliary atresia group. Both ratios were equally as effective as the 5 amino acids listed above in discriminating extrahepatic biliary atresia patients from controls.

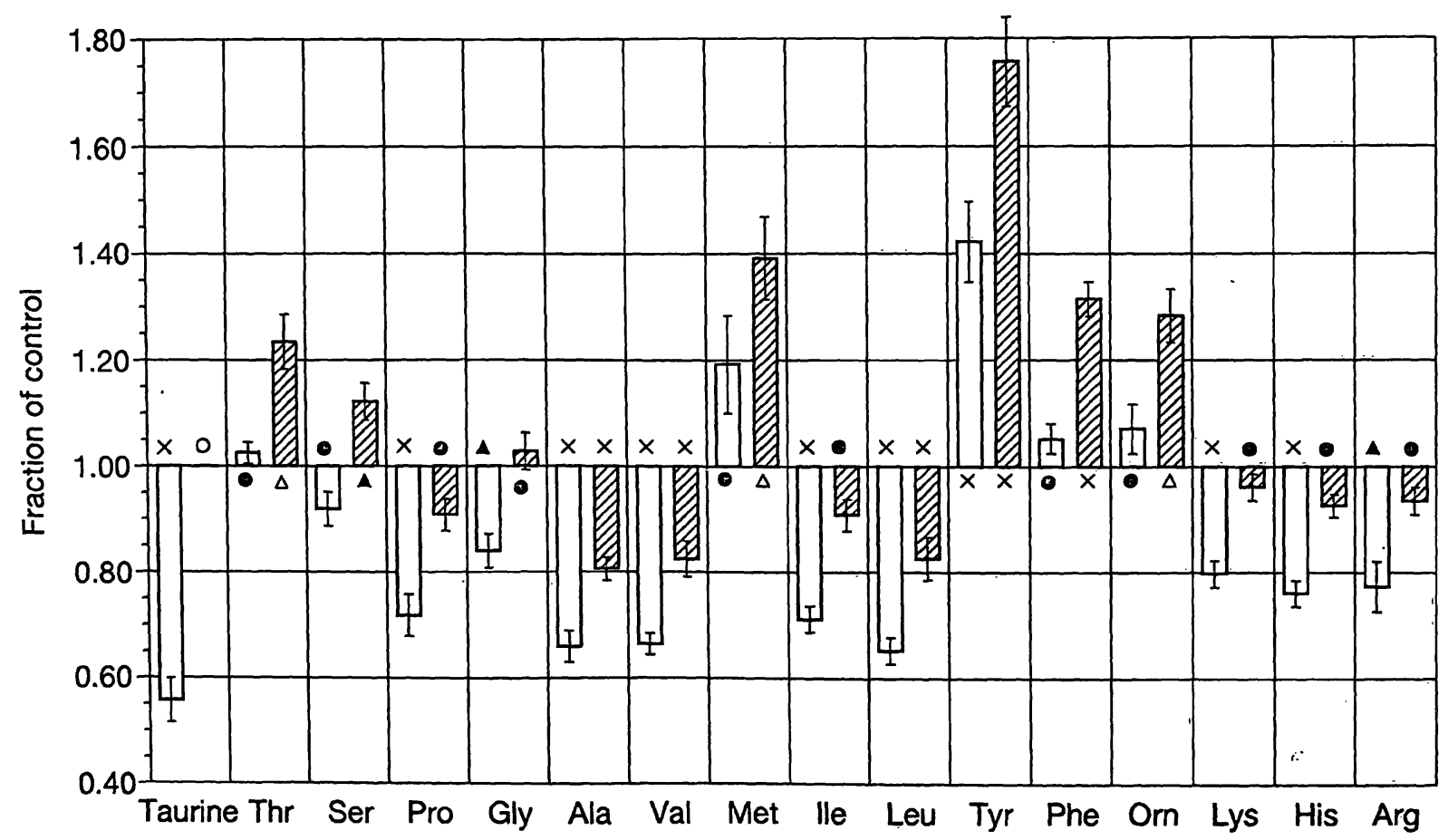

Fig. 1. Absolute (open bars) and relative (hatched bars) fasting plasma concentrations of 16 amino acids in children with extrahepatic biliary atresia and cirrhosis.

Given are mean and SEM of the fractions of the mean control values. Taurine was not included in the molar fraction aminogram (see materials and methods).
$x: \mathrm{p}<0.0005$
A: $\mathrm{p}<0.05$
$\Delta: \mathrm{p}<0.005$
: not significant
o: not measured 


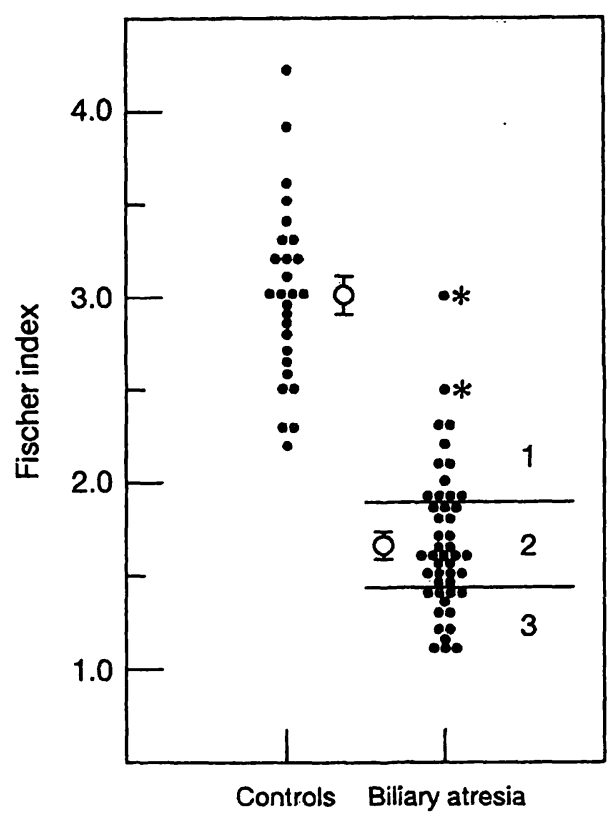

Fig. 2. Comparison of the Fischer index in controls with patients with biliary atresia.

Given are means \pm SEM. The mean numerical value of the Fischer index was very similar to that of the mean valine/tyrosine ratio:

\begin{tabular}{|c|c|c|c|c|}
\hline & Controls & $\mathrm{N}$ & $\begin{array}{l}\text { Biliary atresia } \\
\text { patients }\end{array}$ & $\mathrm{N}$ \\
\hline $\begin{array}{l}\text { Fischer } \\
\text { index }\end{array}$ & $\begin{array}{l}x: \\
3.003 \pm 0.476\end{array}$ & 27 & $\begin{array}{l}x: \\
1.656 \pm 0.394\end{array}$ & 48 \\
\hline $\begin{array}{l}\text { Valine/ } \\
\text { tyrosine }\end{array}$ & $\begin{array}{l}x: \\
3.082 \pm 0.554\end{array}$ & 27 & $\begin{array}{l}x: \\
1.540 \pm 0.548\end{array}$ & 48 \\
\hline
\end{tabular}

$1,2,3)$ shows division of patients into 3 groups according to decreasing intervals of the Fischer index; see fig. 3 and text in Results section.

* Denotes those two patients excluded from the statistical calculations presented in fig. 3 .

Certain amino acid data (tab. 3) showed a significant degree of linear correlation, especially with quantities of hepatic synthetic capacity, with cholestasis and with estimated hepatic blood flow(k). Methionine showed a weak negative correlation with plasma albumin and a negative correlation with estimated hepatic blood flow(k). Leucine was correlated positively only with plasma albumin, and isoleucine was correlated negatively only with cholinesterase. Phenylalanine correlated negatively with cholinesterase and with Quick values. Tyrosine correlated negative with Quick values and with plasma albumin, and positively with partial thromboplastin time. Tyrosine correlated negatively with estimated hepatic blood flow(k) and with the cholestasis marker lipoprotein-X. The Fischer index and the valine/tyrosine quotient both correlated directly with cholinesterase, Quick value, plasma albumin, estimated hepatic blood flow(k) and with lipoprotein-X, and inversely with partial thromboplastin time. Valine (not included in tab. 3) was the only amino acid which correlated positively with the portal venous fraction of liver perfusion $(r=0.33$, $\mathrm{p}<0.05)$.

To investigate further the linear relationships between the Fischer index and some standard laboratory tests, the children with extrahepatic biliary atresia were arbitrarily divided into three groups (fig. 2) approximately according to decreasing 1-SD-decrements from the maximal value of the Fischer index (fig. 2). The group mean values for conventional quantities (tab. 1) of liver function were then analysed for significant differences. It can be seen in figure 3 that decreases in the value of the Fischer index were paralleled by linear changes in the values for plasma albumin, Quick value, estimated hepatic blood flow(k) and in partial thromboplastin time. The differences in the mean values for albumin and estimated hepatic blood flow(k) in groups 1 and 2 were not statistically significant. Total free plasma amino acids did not correlate with body weight percentiles. No individual patient plasma amino acid data in extrahepatic biliary atresia correlated significantly with any of the following quantities: weight percentiles; plasma ammonia; activity of transaminases; bilirubin concentrations; alkaline phosphatase; total serum bile acids or total risk score (data not shown).

\section{Discussion}

The risk scores (3) of our patients were such that none were top priority liver transplantation candidates. Their total free plasma amino acids should therefore have been subject to a relatively small influence by liver cell necrosis $(11,17)$. They differed in this important respect from the children studied by Weisdorf et al. (12). Our patients also had a higher plasma albumin concentration and a better coagulation status than those in that study. To our knowledge this is the first study which compares liver perfusion data with amino acid data in children with extrahepatic biliary atresia and cirrhosis.

The absolute and the fractional plasma amino acid profile in our patients were unbalanced, as described in adult cirrhotics (7-9). Tyrosine was highly increased; there was a trend to higher absolute phenylalanine and methionine values, and branched chain amino acids were decreased. The molar fractional plasma amino acid profile in our group also revealed significant increases in the proportions of tyrosine, phenylalanine and methionine, and reductions in those of branched chain amino acids. 
Tab. 3. Significant statistical correlations between plasma concentrations of individual amino acids, or ratios derived from plasma amino acid data, and conventional quantities of liver function in children with biliary atresia.

\begin{tabular}{|c|c|c|c|c|c|c|c|}
\hline $\mathrm{N}$ & & $\begin{array}{l}\text { Cholin- } \\
\text { esterase } \\
48\end{array}$ & $\begin{array}{l}\text { Albumin } \\
37\end{array}$ & 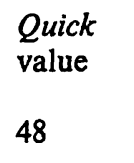 & $\begin{array}{l}\text { Partial } \\
\text { thrombinplastin } \\
\text { time } \\
47\end{array}$ & $\begin{array}{l}\text { Lipoprotein-X } \\
30\end{array}$ & $\begin{array}{l}\text { Estimated hepatic } \\
\text { blood flow(k) } \\
38\end{array}$ \\
\hline Methionine & $\begin{array}{l}\mathrm{r}= \\
\mathrm{p}<\end{array}$ & & $\begin{array}{r}-0.31 \\
0.05\end{array}$ & & & & $\begin{array}{r}-0.33 \\
0.05\end{array}$ \\
\hline Leucine & $\begin{array}{l}r= \\
\mathrm{p}<\end{array}$ & & $\begin{array}{l}0.30 \\
0.05\end{array}$ & & & & \\
\hline Isoleucine & $\begin{array}{l}r= \\
\mathrm{p}<\end{array}$ & $\begin{array}{l}-0.40 \\
0.005\end{array}$ & & & & & \\
\hline Phenylalanine & $\begin{array}{l}r= \\
p<\end{array}$ & $\begin{array}{c}-0.45 \\
0.005\end{array}$ & & $\begin{array}{r}-0.34 \\
0.05\end{array}$ & & & \\
\hline Tyrosine & $\begin{array}{l}r= \\
p<\end{array}$ & & $\begin{array}{r}-0.32 \\
0.05\end{array}$ & $\begin{array}{l}-0.42 \\
0.005\end{array}$ & $\begin{array}{l}0.31 \\
0.05\end{array}$ & $\begin{array}{l}-0.59 \\
0.0005\end{array}$ & $\begin{array}{l}-0.53 \\
0.0005\end{array}$ \\
\hline Valine/Tyrosine & $\begin{array}{l}\mathrm{r}= \\
\mathrm{p}<\end{array}$ & $\begin{array}{l}0.31 \\
0.05\end{array}$ & $\begin{array}{l}0.45 \\
0.005\end{array}$ & $\begin{array}{l}0.44 \\
0.005\end{array}$ & $\begin{array}{l}-0.36 \\
0.005\end{array}$ & $\begin{array}{l}0.48 \\
0.005\end{array}$ & $\begin{array}{l}0.51 \\
0.005\end{array}$ \\
\hline Fischer index & $\begin{array}{l}\mathrm{r}= \\
\mathrm{p}<\end{array}$ & $\begin{array}{l}0.39 \\
0.005\end{array}$ & $\begin{array}{l}0.56 \\
0.005\end{array}$ & $\begin{array}{l}0.50 \\
0.005\end{array}$ & $\begin{array}{c}-0.43 \\
0.005\end{array}$ & $\begin{array}{l}0.37 \\
0.05\end{array}$ & $\begin{array}{l}0.45 \\
0.005\end{array}$ \\
\hline
\end{tabular}

$\mathrm{N}=$ Number of data pairs

For estimated hepatic blood flow(k) see Materials and Methods; Fischer index: Branched chain amino acids (sum of molar plasma concentrations) over aromatic amino acids, tyrosine, phenylalanine (sum of molar plasma concentrations)

In our group, total free plasma amino acids was subnormal, and both essential and non-essential amino acids were equally affected. Weisdorf et al. (12) reported total free plasma amino acids as increased. Like these authors, we found a significant decrease of plasma taurine, which was raised in adult patients (18). Further aberrations were seen in the absolute concentrations of proline, glycine, alanine, lysine and arginine, and in the relative concentrations of threonine, serine and ornithine.
The plasma amino acid profile in cirrhosis is complexly related to the extent of protein-calorie deficiency, residual liver function, liver perfusion, impaired hormone function, and vitamin status $(19,20$, 21). While the plasma amino acid profile in our patients was not totally typical for protein-calorie malnutrition $(21,22)$, their general hypoaminoacidaemia and deficiency of important substrates of glucogenesis, especially alanine $(23,24)$, are seen as signs of severe protein-calorie deficiency $(20,22,25)$, possibly

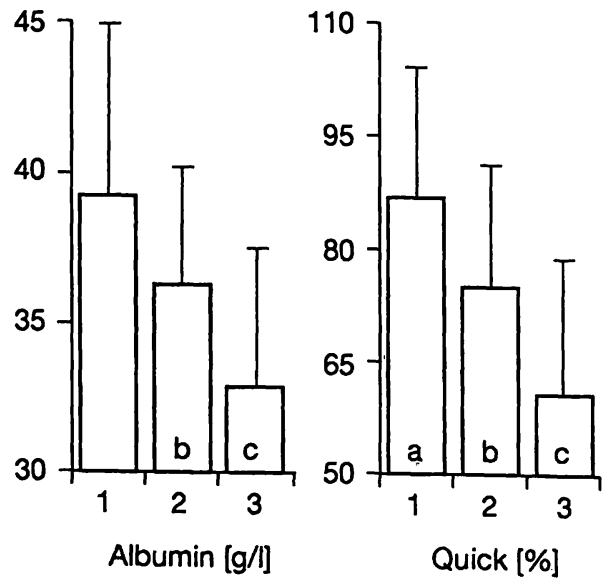

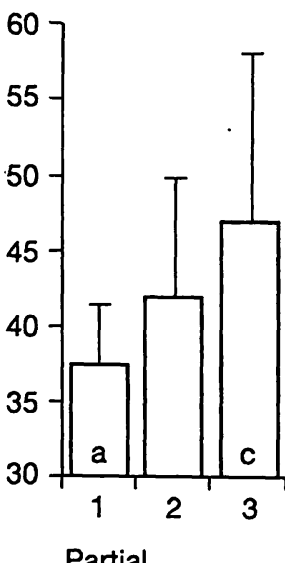

thromboplastin time [s] Fig. 3. Comparison of mean values of standard laboratory tests in patients after arbitrary separation into 3 groups according to
1 SD decrements in the Fischer index value.

Depicted are mean values and standard error of the mean. Units are as in table 1.

1) Group 1, Fischer index: $2.274-1.865(\mathrm{n}=12)$.

2) Group 2, Fischer index: $1.864-1.455(\mathrm{n}=22)$.

3) Group 3, Fischer index: $1.454-1.045(\mathrm{n}=14)$.

a) 1 vs $2: \mathrm{p}<0.05$

b) 2 vs 3: $\mathrm{p}<0.05$

$\operatorname{EHBF}(\mathrm{k})=$ c) 1 vs $3: \mathrm{p}<0.05$

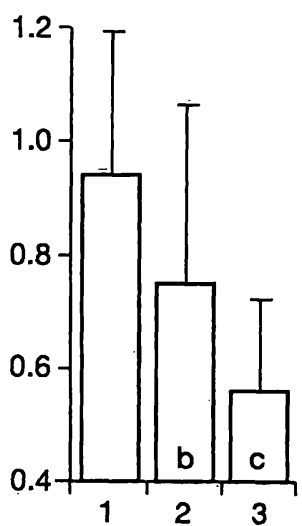

EHBF (k) [min $\left.{ }^{-1}\right]$

\footnotetext{
EHBF(K) = rate constant of elimination proportional to estimated hepatic blood flow.
} 
due to hypermetabolism and poor nutrient absorption $(26,27)$. We have no evidence that their taurine deficit resulted from dietary amino acid deficiencies as suggested by others (12). Increased formation of taurineconjugated bile acids (28) may have reduced their taurine reserves.

Hyperammonaemia in our patients was not correlated with plasma concentrations of branched chain amino acids or with Fischer index values $(29,30,31)$. Lack of correlation of plasma branched chain amino acids with estimated hepatic blood flow(k) and the presence of normoglycaemia also speak against inadequate degradation of insulin $(19,29,32)$ as the reason for their low plasma branched chain amino acids. In our patients, leucine, which is ketogenic, showed an abnormally high correlation with valine, which is gluconeogenic. Compared with controls, the normally strong correlation of valine with isoleucine was weaker. In calorie deprivation branched chain amino acids may become a source of fuel for muscle $(19,33$, 34). We postulate that in our extrahepatic biliary atresia children the branched chain amino acids deficit resulted from their use as alternative energy substrates, and that the low concentrations of these amino acids may indicate increased dietary requirements for them (35).

In our probands, plasma tyrosine correlated inversely with estimated hepatic blood flow(k), indicating that reduced hepatic extraction of systemic tyrosine (36, 37) may be a cause of hypertyrosinaemia in cirrhosis due to extrahepatic biliary atresia. Reduced intracellular activity of hepatic tyrosine amino transaminase in cirrhotics has not been confirmed $(38,39)$.

In our hands, the discriminate function analysis of a combination of five plasma amino acids provided a highly accurate segregation of individual extrahepatic biliary atresia patients at early stages of cirrhotic alteration from controls. The mean value and the standard deviation of the Fischer index in our control collective were very similar to published values for adult controls $(8,9,10)$ and healthy children (12). Decreases in the Val/Tyr ratio and in the Fischer index were measurable in our patients before hepatic failure

\section{References}

1. Alagille, D. (1984) Extrahepatic biliary atresia. Hepatology 4, 7-10.

2. Howard, E. R. \& Tan, K. C. (1989) Biliary atresia. Br. J. Hosp. Med. 41, $123-130$.

3. Burdelski, M., Ringe, B., Rodeck, B., Hoyer, P. F., Brodehl, J. \& Pichlmayr, R. (1988) Indikationen und Ergebnisse der Lebertransplantation im Kindesalter. Monatsschr. Kinderheilkd. 136, 317-322. had become critical. In our study, both ratios discriminated patients from controls as effectively as the combination of 5 amino acids listed above. Several of the amino acid data correlated well with certain conventional quantities of hepatic function, especially with synthetic capacity. The analysis of variance of the mean values of standard quantities in the three groups of children with extrahepatic biliary atresia showed that the Fischer index decreased linearly with decreasing liver synthetic function, as in adults $(9$, 10). Two of the quantities, cholinesterase and Quick value of the prognostic risk score (3) used in our hospital, correlated significantly with amino acid data, whereas the total risk score did not.

Concerning the prognostic value of the Fischer index, only 18 of our 48 patients could be followed up for a period of 2 years. In 9 of these, the Fischer index value was greater than 1.5. Of these, 1 died within 6 months, 1 within 18 months, but the remaining 7 survived for up to 24 months after the initial investigation. On the other hand, in the group of 9 patients with values less than 1.5 , three had died within 6 months, 6 others within 18 months, and only 1 was alive 24 months later.

We therefore conclude that in children with extrahepatic biliary atresia and cirrhosis, the valine/tyrosine ratio and the Fischer index are good indicators of hepatic synthetic capacity, that plasma tyrosine concentration correlates with estimated hepatic blood flow and with cholestasis, and that these indicators and the plasma amino acid profile should be used in the biochemical and nutritional $(35,40)$ evaluation of patients awaiting liver transplantation.

\section{Acknowledgements}

The data presented here were extracted from the inaugural dissertation of A. Wiltfang, Medizinische Hochschule Hannover, 1992. We are especially grateful to Drs. Jörg-Andreas Müller and Christiane Ehrenheim (Dept. of Nuclear Medicine, Medizinische Hochschule Hannover) for discussions of scintigraphic data on liver perfusion, and to Drs. Hartmuth Herrmann and Maria Török (Dept. of Biometrics, Medizinische HochschuleHannover) for support in the statistical evaluation of the data presented here.
4. Kasai, M. (1974) Treatment of biliary atresia with special reference to hepatic portoenterostomy and its modifications. Prog. Ped. Surg. 6, 5-52.

5. Kasai, M., Watanabe, I. \& Ohi, R. (1975) Follow-up studies of long-term survivors after hepatic portoenterostomy for 'non-correctable' biliary atresia. J. Ped. Surg. 10, 173-182.

6. Alagille, D., Laurent, J. \& Roy, C. C. (1989) Is there still a place for the Kasai procedure in the treatment of extrahepatic biliary atresia? Editorial. J. Pediatr. Gastroenterol. Nutr. 9, 405-406. 
7. Iber, F. L., Rosen, H., Levenson, S. M. \& Chalmers, T. C. (1957) The plasma amino acids in patients with liver failure. J. Lab. Clin. Med. 50, 417-425.

8. Fischer, J. E., Funovics, J. M., Aguirre, A., James, J. H., Keane, J. M., Wesdorp, R. I., Yoshimura, N. \& Westman, T. (1975) The role of plasma amino acids in hepatic encephalopathy. Surgery 78, 276-290.

9. Mc Cullough, A. J., Czaja, A. J., Jones, J. D. \& Go, V. L. (1981) The nature and prognostic significance of serial amino acid determinations in severe chronic active liver disease. Gastroenterology 81, 645-652.

10. Morgan, M. Y., Milsom, J. P. \& Sherlock, S. (1978) Plasma ratio of valine, leucine and isoleucine to phenylalanine and tyrosine in liver disease. Gut 19,1068-1073.

11. Morgan, M. Y., Marshall, A. W., Milsom, J. P. \& Sherlock, S. (1982) Plasma amino-acid patterns in liver disease. Gut $23,362-370$.

12. Weisdorf, S. A., Freese, D. K., Fath, J. J., Tsai, M. Y. \& Cerra, F. B. (1987) Amino acid abnormalities in infants with extrahepatic biliary atresia and cirrhosis. J. Pediatr. Gastroenterol. Nutr. 6, 860-864.

13. Rau, J. (1988) Wachstum und Entwicklung; Referenzwerte für das Kindesalter. In: Kinderheilkunde, 6th edn. (Sitzmann, F. C., ed.) pp. 983-1038, Hippokrates Verlag, Stuttgart.

14. Talafant, E. \& Tovarek, J. (1981) Enzymatic determination of lipoprotein-X, a specific serum cholestasis marker. J. Clin. Chem. Clin. Biochem. 19, 155-157.

15. Creutzig, H. (1985) Radionuclide techniques in the follow up of liver-transplanted patients. In: Progress in Liver Tiansplantation (Gips, C. H., ed.) pp. 159-171, Nijhoff, The Hague.

16. Biersack, H.-J. (1980) Die quantitative LeberperfusionsSzintigraphie. Tierexperimentelle und klinische Untersuchungen bei normaler und pathologischer Leberdurchblutung. Langenbecks. Arch. Chir. 351, 23-37.

17. Higashi, T. (1982) Impaired metabolism of methionine in severe liver diseases. I. Clinical and pathophysiological significance of elevated serum methionine levels. Gastroenterol. Jpn. 17, 117-124.

18. Wiltfang, J. \& Jaugsch, F. (1987) Untersuchung elektrophysiologischer (VEP), biochemischer und psychometrischer Parameter bei hepatischer Enzephalopathie, Hannover, Med. Hochschule, Diss.

19. Munro, H. N. (1982) Metabolic integration of organs in health and disease. J. Parenter. Enteral. Nutr. 6, 271-279.

20. Bremer, H. J., Duran, M., Kamerling, J. P., Przyrembel, H. \& Wadman, S. K. (1981) Disturbances of Amino Acid Metabolism, p. 404, Urban and Schwarzenberg, München.

21. Lumeng, L. \& Li, T. K. (1974) Vitamin B6 metabolism in chronic alcohol abuse: Pyridoxal phosphate synthesis and degradation in human erythrocytes. J. Clin. Invest. 53, 693-704.

22. Holt, L. E. Jr., Snyderman, S. E., Norton, P. M., Roitman, E. \& Finch, J. (1963) The plasma aminogram in kwashiorkor. Lancet II, 1343-1348.

23. Felig, P. (1973) The glucose-alanine cycle. Metabolism 22, 179-207.

24. Senior, B. \& Sadeghi-Nejad, A. (1989) Hypoglycemia: A pathophysiologic approach. Acta. Paediatr. Scand. 352 (Suppl.), 1-27.

25. Ghisolfi, J., Charlet, P., Ser, N., Salvatore, R., Thouvenot, J. P. \& Duole, C. (1978) Plasma free amino acids in normal children and in patients with proteino-caloric malnutrition fasting and infection. Pediatr. Res. 12, 912-917.
26. Pierro, A., Koletzko, B., Carnielli, V., Superina, R. A., Roberts, E. A., Filler, R. M., Smith, J. \& Heim, T. (1989) Resting energy expenditure is increased in infants and children with extrahepatic biliary atresia. J. Ped. Surg. 24, 534-538.

27. Weisdorf, S. A., Lysne, J. L. \& Cerra, F. B. (1986) Total parenteral nutrition in hepatic failure and transplantation. In: Total Parenteral Nutrition: Indication, Utilization, Complications, and Pathophysiological Considerations (Lebenthal, E., ed.) pp. 463-474, Raven Press, New York.

28. Linnet, K. \& Kelbaek, H. (1982) The patterns of glycine and taurine conjugates of bile acids in serum in hepatobiliary disease. Scand. J. Gastroenterol. 17, 919-924.

29. Leweling, H., Staedt, U., Tschepe, A., Striebel, J.-P., Langhans, W. \& Holm, E. (1984) Verzweigtkettige Aminosäuren in der parenteralen Ernährung bei Leberzirrhose. Krankenhausarzt $37,1-16$.

30. Hayashi, M., Ohnishi, H., Kawade, Y., Muto, Y. \& Takahashi, Y. (1981) Augmented utilisation of branched-chain amino acids by skeletal muscle in decompensated liver cirrhosis in special relation to ammonia detoxication. Gastroenterol. Jpn. 16, 64-70.

31. Häussinger, D., Meijer, A. J., Gerok, W. \& Sies, H. (1988) Hepatic nitrogen metabolism and acid-base homeostasis. In: pH Homeostasis (Häussinger, D., ed.) pp. 337-377, Academic, London.

32. James, J. H., Jeppsson, B., Ziparo, V. \& Fischer, J. E. (1979) Hyperammonaemia, plasma amino acid imbalance, and blood-brain amino acid transport: A unified theory of portal-systemic encephalopathy. Lancet $13,772-775$.

33. Adibi, S. A. (1980) Roles of branched chain amino acids in metabolic regulation. J. Lab. Clin. Med. 95, 475-484.

34. Byrd, D. J., Krohn, H.-P., Winkler, L., Steinborn, C., Hadam, M., Brodehl, J. \& Hunneman, D. H. (1989) Neonatal pyruvate dehydrogenase deficiency with lipoate responsive lactic acidaemia and hyperammonaemia. Eur. J. Pediatr. 148, 543-547.

35. Cerra, F. B., Cheung, N. K., Fischer, J. E., Kaplowitz, N., Schiff, E. R., Dienstag, J. L., Bower, R. H., Mabry, C. D. Leevy, C. M. \& Kiernan, T. (1985) Disease specific amino acid infusion (F080) in hepatic encephalopathy: A prospective, randomized, double-blind, controlled trial. J. Parenter. Enteral. Nutr. 9, 288-295.

36. Kilberg, M. S. (1989) Regulation of hepatic amino acid transport and partial purification of the system A carrier. In: Hepatic Transport in Organic Substances (Petzinger, E., Kinne, R. K. H. \& Sies, H., eds) pp. 167-176, SpringerVerlag, Berlin-Heidelberg.

37. Ali, F. M., Ansley, J. \& Faraj, B. A. (1980) Studies of the influence of portocaval shunt on the metabolism of tyrosine. J. Pharmacol. Exp. Ther. 214, 546.

38. Andersson, S. M., Salaspuro, M. \& Ohisalo, J. J. (1982) Metabolic basis of hypertyrosinemia in liver disease. Gas= troenterology $82,554-557$.

39. Henderson, J. M., Faraj, B. A., Ali, F. M. \& Rudman, D. (1981) Tyrosine transaminase activity in normal and cirrhotic liver. Dig. Dis. Sci. 26, 124-128.

40. Kelts, D. G., Ney, D., Bay, C., Saudubray, J.-M. \& Nyhan, W. L. (1985) Studies on requirements for amino acids in infants with disorders of amino acid metabolism. I. Effect of alanine. Ped. Res. 19, 86-91.

Dr. rer. nat. D. J. Byrd

Medizinische Hochschule Hañnover

Kinderheilkunde II

Pädiatrische Nieren- und

Stoffwechselkrankheiten

Postfach 610180

W-3000 Hannover 61

Bundesrepublik Deutschland 